\title{
Clinical Profile of Neonatal Early Onset Sepsis: A Study on the Current Scenario
}

\author{
Kiran C Pankaj ${ }^{\circledR 1}$, Sristi Ganguly ${ }^{\circledR 2}$, Manas R Upadhyay ${ }^{\circledR 3}$ \\ ${ }^{1}$ Assistant Professor, Department of Pediatrics, Pt. J. N. M. Medical College, Raipur, Chattisgarh, India, ${ }^{2}$ Senior Resident, Department of Pediatrics, SVPPGIP, SCBMCH, \\ Cuttack, Odisha, India, ${ }^{3}$ Assistant Professor, Department of Pediatrics, SVPPGIP, SCBMCH, Cuttack, Odisha, India.
}

\section{Abstract}

Background: Neonatal early onset sepsis remains to be a challenge in India, owing to its variable presentation, diagnostic difficulty and high fatality. An attempt needs to be made to study its clinical profile for easy identification of such babies, with new antibiotic guidelines formulated based on current microorganisms isolated. The aim of the study is to study the clinical profile of early onset sepsis in neonates in terms of the risk factors, clinical factors and etiology, and ascertain factors associated with definite sepsis. Subjects and Methods: This hospital based cross-sectional study enrolled neonates with suspected early onset sepsis. Those with congenital anomalies, surgical conditions, gestation $<28$ weeks and birth weight $<1 \mathrm{~kg}$ excluded. Subjects were subjected to sepsis screen and blood culture, and their perinatal history recorded. Blood culture positive babies were considered to have definite sepsis. Data was analysed using Chi square with SPSS 18 . Results: Among 300 babies enrolled, 70 babies had definite sepsis. The most common organism isolated was Klebsiella (27.1\%) and Staphylococcus hemolyticus (21.4\%), most showing sensitivity to Ampicillin and Gentamicin. Respiratory distress was the commonest presentation (71.3\%). A significant association with definite sepsis was seen with prematurity $(\mathrm{p}=0.0026)$ and low birth weight $(\mathrm{p}=0.0052)$, perinatal risk factors namely premature rupture of membranes $(\mathrm{p}=0.004)$, foul smelling liquor $(\mathrm{p}=0.016)$ and birth asphyxia ( $\mathrm{p}$-value $=0.02) .28 .3 \%$ had positive sepsis screen, which was significant $(\mathrm{p}=0.001)$. Conclusion: Early onset sepsis needs prompt identification and treatment initiation, possible with aid of sepsis screen and high index of suspicion with certain perinatal risk factors and gestational age and birth weight.

Keywords: Neonatal sepsis, clinical profile, risk factors

Corresponding Author: Kiran C Pankaj, Assistant Professor, Department of Pediatrics, Pt. J. N. M. Medical College, Raipur, Chattisgarh, India. E-mail: kiran.pankaj7@gmail.com

Received: 17 May 2020

Revised: 11 June 2020

Accepted: 25 June 2020

Published: 9 July 2020

\section{Introduction}

Neonatal septicaemia continues to be one of the major threats that neonatology continues to face since time immemorial. Though it contributes to $25 \%$ of the deaths worldwide, ${ }^{[1]}$ but causes $50 \%$ of the deaths in developing countries. ${ }^{[2]}$ Despite extensive care in hospitals, with inotropic and ventilator support, $2 \%$ of term and $20 \%$ of preterms still succumb to early onset sepsis. ${ }^{[3]}$

Early onset sepsis, arising from neonates' immunological immaturity, ${ }^{[4]}$ further poses another challenge to physicians, as the presentations of such babies are often vague and variable, making it difficult to identify. ${ }^{[5]}$ Though blood culture remains the gold standard for diagnosis of sepsis, ${ }^{[6]}$ the unavailability of these facilities and delay in receiving reports, prompt need for other measures to initiate treatment.

Considering the evolving nature of early onset sepsis, the changing microbiological and risk spectrum across the land, it is imperative to furnish more studies regarding the clinical profile of early onset sepsis, in an attempt to acknowledge any changes and updates, with an effort to formulate our new protocols accordingly. Not only will this help us allocate resources appropriately to those in more need in resource limited countries, but also save considerable damage that can befall those babies and consequently, the nation.

\section{Subjects and Methods}

\section{Design settings}

A hospital based cross-sectional study was conducted during the period February 2019 to July 2019 among the neonates of tertiary care hospital, the highest referral center in Odisha. Ethical clearance was obtained from the Institutional Ethical Committee prior to start of the study.

\section{Inclusion and exclusion criteria}


All the neonates admitted in neonatal ward with suspected early onset sepsis with age within 72 hours. Neonates with TORCH infections, congenital anomalies, syndromic baby or with surgical conditions have been excluded from the study. Newborns with gestational age less than 28 weeks and with birth weight less than a kilogram were also excluded.

\section{Method of collection of data}

All the eligible neonates were registered in the study after obtaining informed consent from the patient attendants.

Their antenatal history was recorded, either from antenatal records, pregnancy cards, referral letters or history by ASHA workers or mothers themselves, in this order of preference. The perinatal risk factors considered in our study were sevenLow birth weight, prolonged labour, premature rupture of membranes, foul smelling liquor, maternal fever, unclean vaginal examination and perinatal asphyxia. The definitions of these risk factors have been listed in [Table 1]. ${ }^{[7]}$

The neonates were subjected to sepsis screen consisting of total leukocyte count $\left(<5000 / \mathrm{mm}^{3}\right)$, Absolute neutrophil count (Low as per Munroe chart for term and Mouzinho's chart for very low birth weight infants), micro- erythrocyte Sedimentation Rate $(<15 \mathrm{mmHg}$ in first hour), immature to total neutrophil ratio $(>0.2)$ and C-reactive protein $(>1 \mathrm{mg} / \mathrm{dl})$. The sepsis screen was positive if at least two out of the five criteria were satisfied. ${ }^{[8,9]}$

Blood culture (BACTEC) was taken from all the babies, prior to administration of antibiotics. Samples were collected with all aseptic precaution, from a peripheral veni-puncture site. $1 \mathrm{ml}-3 \mathrm{ml}$ sample of blood was added to a paediatric BacT/ALERT blood culture bottle. Bacteria thus isolated were identified, and antimicrobial susceptibility testing was done using Vitek 2 compact system. Those neonates which showed growth on blood culture were considered to have definite sepsis.

\section{Data analysis}

All the data was collected and compiled systematically. Data was evaluated with SPSS version 18.0 and analysed with Chi-square test and percentages, with $\mathrm{p}$ value $<0.05$ being considered significant.

\section{Results}

A total of 300 new-borns were recruited in the study, who were all suspected to have early onset sepsis. A little above half of them (57\%) were term gestation and $65.6 \%$ were male. Low birth weight babies comprised $49.6 \%$ of the population, and $42.3 \%$ of them were delivered by Caesarean section. The average length of hospital stay was 4.43 days. Though most of them recovered, $12.3 \%$ succumbed to death. [Table 2]
The incidence of blood culture positivity among the neonates suspected to have early onset sepsis was $23.3 \%$ ( 70 out of 300 ). These babies were thus considered to have definite sepsis and the rest, as probable/ clinical sepsis.

2 out of 40 had cerebrospinal fluid culture positive i.e. $5 \%$, both of which had growth in blood culture. 1 out of $10(1 \%)$ had urine culture positive, which was also blood culture positive.

On comparing the perinatal risk factors present in the study population, leading the list was birth asphyxia (22.6\%) followed by premature rupture of membranes (20.6\%). Similarly, if we were to consider the commonest perinatal risk factors in the infants with definite sepsis, a similar trend was noted. Foul smelling liquor was seen in $8.6 \%$ of the cases, of which $42.3 \%$ had definite sepsis. [Table 3 ]

The clinical presentation of these neonates were varied and tabulated in table 4. Out of the clinical features noted in the newborns in the study population, the most frequently encountered were respiratory distress $(71.3 \%)$, refusal to feed $(59 \%)$ and lethargy (55\%). The same trend was maintained in babies with definite sepsis.

$28.3 \%$ of the study population had a positive sepsis screen, of which $44.7 \%$ had definite sepsis. The association between positive sepsis screen and definite sepsis was further established to be significant, with $\mathrm{p}$-value being 0.0001 .

The organisms responsible for early onset sepsis, as grown in our study [Figure 1], were Klebsiella pneumonia (27.1\%) followed by Staphylococcus hemolyticus (21.4\%), Acinetobacter (12.8\%), E. coli (8.5\%) and Staphylococcus aureus (8.5\%). Most organisms isolated in the study showed sensitivity to Ampicillin, Gentamicin, Amikacin and Cefotaxime.

A significant association was noted with various characteristics of the neonates with definite sepsis, namely prematurity ( $p$ - value $=0.0026)$ and low birth weight ( $p$-value $=0.0052$ ) The mode of delivery and sex of the child were insignificant. Among the perinatal risk factors, premature rupture of membranes, foul smelling liquor and birth asphyxia, were also found to be significantly associated with definite sepsis, with their p- values being $0.004,0.016$ and 0.02 respectively. Others such as maternal fever, unclean vaginal examinations and prolonged labour, however, were not found to be significant. Furthermore, all the clinical features except vomiting and irritability were also found to have significant association with culture-positive sepsis.

\section{Discussion}

A total of 300 neonates were admitted with suspected early onset sepsis, and their clinical profile studied.

The male to female ratio in the study population was 1.91 , with $65.6 \%$ being male. $19.7 \%$ of the males and $30 \%$ of the 
Table 1: Definition of perinatal risk factors

\begin{tabular}{|c|c|}
\hline 1. Prolonged rupture of membranes (PROM) & Interval between rupture of membranes and birth of baby $>18$ hours. \\
\hline 2. History of Maternal Fever (MF) & $\begin{array}{l}\text { Fever in mother }>38^{\circ} \mathrm{C} \text { before delivery with evidence of bacterial infection in } \\
\text { the mother in haemogram or culture. Exclusion of malaria by peripheral blood } \\
\text { film examination. }\end{array}$ \\
\hline 3. Low birth weight Prematurity (LBW) & $<2500 \mathrm{~g},>37$ weeks \\
\hline 4. Foul smelling liquor (FSL) & $\begin{array}{l}\text { Abnormal smell of liquor as perceived by attending obstetrician or neonatologist. } \\
\text { Frankly purulent liquor. }\end{array}$ \\
\hline 6. Birth asphyxia (BA) & $\begin{array}{l}\text { Apgar score at } 5 \text { minute }<6 \text { and/or requirement of IPPR for resuscitation or } \\
\text { endotracheal intubation }\end{array}$ \\
\hline 7. Unclean vaginal examination (UVE) & $\begin{array}{l}\text { Vaginal examination performed: - }- \text { without gloves }- \text { with unsterile gloves - } \\
\text { any vaginal examination performed by an untrained birth attendant. }\end{array}$ \\
\hline
\end{tabular}

\begin{tabular}{|c|c|c|c|c|}
\hline Characteristics & & Percentage $(\mathrm{N}=300)$ & Definite Sepsis & P-VALUE* \\
\hline \multirow[t]{2}{*}{ Gestational Age } & Term & $171(57 \%)$ & $29(16.9 \%)$ & 0.0026 \\
\hline & Pre-Term & $129(43 \%)$ & $41(31.7 \%)$ & \\
\hline \multirow[t]{2}{*}{ Sex } & Female & $103(34.3 \%)$ & $31(30 \%)$ & 0.045 \\
\hline & Male & $197(65.6 \%)$ & $39(19.7 \%)$ & \\
\hline \multirow[t]{2}{*}{ Birth Weight } & $\geq 2.5 \mathrm{~kg}$ & $151(50.4 \%)$ & $25(16.5 \%)$ & 0.0052 \\
\hline & $\leq 2.5 \mathrm{~kg}$ & $149(49.6 \%)$ & $45(30.2 \%)$ & \\
\hline \multirow[t]{2}{*}{ Mode Of Delivery } & NVD & $173(57.6 \%)$ & $34(19.6 \%)$ & 0.078 \\
\hline & LSCS & $127(42.3 \%)$ & $36(28.3 \%)$ & \\
\hline \multirow[t]{2}{*}{ Sepsis Screen } & Negative & $215(71.6 \%)$ & $32(14.8 \%)$ & 0.0001 \\
\hline & Positive & $85(28.3 \%)$ & $38(44.7 \%)$ & \\
\hline \multirow[t]{2}{*}{ Outcome } & Discharge & $263(87.6 \%)$ & $33(12.5 \%)$ & \\
\hline & Death & $37(12.3 \%)$ & $37(100 \%)$ & \\
\hline
\end{tabular}

$* \mathrm{P}$-value $<0.05$ is significant

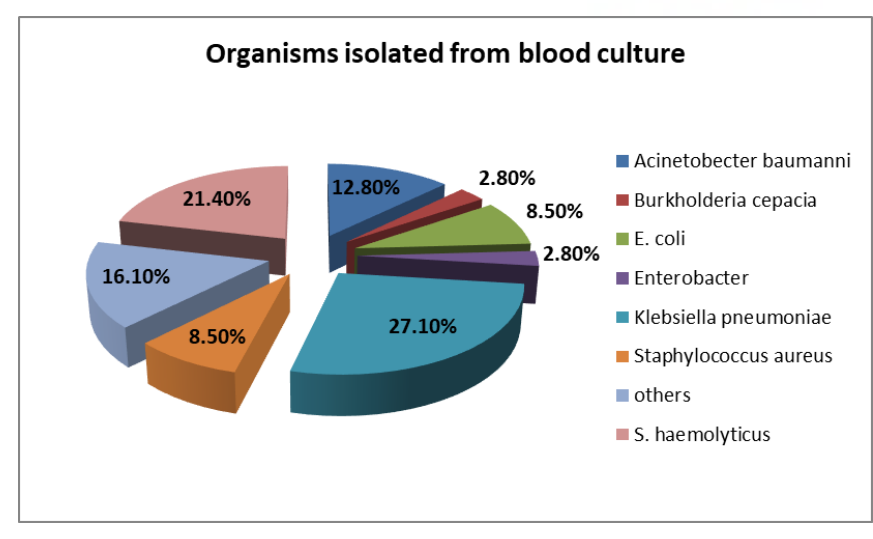

Figure 1: Organisms isolated from blood culture females were confirmed to have blood culture positive sepsis, the association being statistically significant ( $\mathrm{p}$-value $=0.045$ ). In a study done by Fareedul et $\mathrm{al}^{\left[{ }^{[10]}\right.}$ a similar trend was noticed where $26.5 \%$ of the males and $37 \%$ of the females were diagnosed with definite sepsis.

Similarly, a significant association was also seen with prematurity ( $p$-value $=0.0026$ ), which is in line with studies done by Murthy et al and Oddie et al. ${ }^{[11][12]}$ Lower gestation is associated with immature innate immune responses and deprivation of maternally-derived, passively-acquired, pathogen-specific antibody. In our study, $31.7 \%$ of the preterm babies had definite sepsis as compared to $16.9 \%$ of the term babies.

149 out of 300 babies were low birth weight i.e. $49.6 \%$. A higher incidence of culture positive sepsis was seen in low birth weight babies (30.2\%) as compared to rest (16.5\%), with $\mathrm{p}$-value being 0.0052 . Various other studies done by Shah et al, ${ }^{[13]}$ Meenu et al and Murthy et al. ${ }^{[7][11]}$ also confirmed a 


\begin{tabular}{llll}
\hline \multicolumn{4}{|c}{ Table 3: Incidence of risk factors in relation to definite sepsis } \\
\hline Risk factors & $\begin{array}{l}\text { Percentage } \\
(\mathrm{N}=300)\end{array}$ & $\begin{array}{l}\text { Definite } \\
\text { Sepsis }\end{array}$ & P-Value \\
\hline $\begin{array}{l}\text { Premature } \\
\text { rupture of } \\
\text { membranes }\end{array}$ & $62(20.6 \%)$ & $23(37 \%)$ & 0.004 \\
$\begin{array}{l}\text { Maternal } \\
\text { fever }\end{array}$ & $3(1 \%)$ & $1(33.3 \%)$ & 0.68 \\
\hline $\begin{array}{l}\text { Foul } \\
\text { smelling } \\
\text { liqour }\end{array}$ & $26(8.6 \%)$ & 11 & 0.016 \\
$\begin{array}{l}\text { Prolonged } \\
\text { labour }\end{array}$ & $15(5 \%)$ & $6(40 \%)$ & 0.11 \\
$\begin{array}{l}\text { Birth } \\
\text { asphyxia }\end{array}$ & $68(22.6 \%)$ & $\begin{array}{l}23 \\
(33.8 \%)\end{array}$ & 0.02 \\
$\begin{array}{l}\text { Unclean } \\
\text { vaginal } \\
\text { examina- } \\
\text { tions }\end{array}$ & $11(3.6 \%)$ & $4(36.3 \%)$ & 0.29 \\
\hline $\begin{array}{l}\text { Low birth } \\
\text { weight }\end{array}$ & $149(49.6 \%)$ & $\begin{array}{l}45 \\
(30.2 \%)\end{array}$ & 0.0052 \\
\hline
\end{tabular}

*percentages may not add up as one baby may have more than 1 risk factor. $\$$ P-value $<0.05$ is significant

\begin{tabular}{llll}
\hline \multicolumn{4}{l}{ Table 4: Clinical feature in relation to definite sepsis } \\
\hline $\begin{array}{l}\text { Clinical fea- } \\
\text { ture }\end{array}$ & $\begin{array}{l}\text { Percentage } \\
(\mathrm{N}=300)\end{array}$ & $\begin{array}{l}\text { Definite } \\
\text { Sepsis }\end{array}$ & P-Value \\
\hline $\begin{array}{l}\text { Respiratory } \\
\text { distress }\end{array}$ & $214(71.3 \%)$ & $65(30.3 \%)$ & 0.0001 \\
\hline $\begin{array}{l}\text { Tachycardia } \\
\text { Poor pulse }\end{array}$ & $76(15.3 \%)$ & $15(32.6 \%)$ & 0.025 \\
Cyanosis & $22(7.3 \%)$ & $42(57.5 \%)$ & 0.0001 \\
\hline $\begin{array}{l}\text { Prolonged } \\
\text { CRT }\end{array}$ & $68(22.6 \%)$ & $38(55.8 \%)$ & 0.0001 \\
$\begin{array}{l}\text { Convulsion } \\
\text { Irritability }\end{array}$ & $57(19 \%)$ & $21(36.8 \%)$ & 0.007 \\
$\begin{array}{l}\text { Refusal of } \\
\text { feeding }\end{array}$ & $177(59 \%)$ & $53(27.7 \%)$ & 0.64 \\
\hline $\begin{array}{l}\text { Lethargy } \\
\text { Vomiting }\end{array}$ & $165(55 \%)$ & $50(30.3 \%)$ & 0.0001 \\
$\begin{array}{l}\text { Temperature } \\
\text { instability }\end{array}$ & $56(18.6 \%)$ & $40(71.4 \%)$ & 0.001 \\
\hline
\end{tabular}

*percentages may not add up as one case may have more than 1 clinical feature.

$\$$ P-value $<0.05$ is significant significant association between low birth weight and definite sepsis. Though prematurity and low birth weight are used in place of each other, and constitute confounding factors in studies, the increased risk of neonatal EOS is more strongly associated with low gestational age than with birth weight. ${ }^{[14]}$

$57.6 \%$ of the newborns were born out of normal vaginal delivery. The incidence of definite sepsis was higher in those newborns delivered by caesarean section. The mortality rate in our study was $12.3 \%$. However, all 37 neonates who died were blood culture positive. The mortality rate in our study was bit higher than that reported in DeNIS $2016(8.6 \%),{ }^{[15]}$ the difference probably being due to the fact that our study had many out born, rather than only intramural babies, which could lead to delay in the initial treatment.

Numerous perinatal risk factors were assessed in the study namely premature rupture of membranes, prolonged labour, foul smelling liquor, low birth weight, maternal fever, birth asphyxia and unclean vaginal examination. $49.6 \%$ were low birth weight, $22.6 \%$ had birth asphyxia, $20.6 \%$ premature rupture of membranes, $8.6 \%$ had foul smelling liquor and $5 \%$ had prolonged labour. One third of our population (33.3\%), however, had no perinatal risk factors.

Studies done by Mamta et al, ${ }^{[16]}$ Meenu et al and Agarwal et al reveal that birth asphyxia was one of the commonest perinatal risk factors responsible for early onset sepsis. ${ }^{[7][17]}$ A significant association was noted between birth asphyxia and definite sepsis, with p-value 0.02 . Like in studies done by Oddie et al, ${ }^{[12]}$ and Murthy et ${ }^{1},{ }^{[11]}$ premature rupture of membranes was noted to be significantly associated with definite sepsis. Previous studies done by Betty et al, ${ }^{[18]}$ and Shah et al, ${ }^{[13]}$ also observed foul smelling liquor to significantly associated with neonatal sepsis, like in our study.

With respect to clinical features, respiratory distress was the most common presentation $(71.3 \%)$ followed by refusal to feed $(59 \%)$ and lethargy $(55 \%)$. Signs of shock i.e. tachycardia (15.3\%), prolonged capillary refill time (22.6\%) and poor pulses $(24.3 \%)$ were also identified. Convulsions comprised $19 \%$ of the study population where as $18.6 \%$ had temperature instability. Comparable to our study, Bhishma et al, ${ }^{[19]}$ Fareedul et al, ${ }^{[10]}$ and Basu et al, ${ }^{[20]}$ found respiratory distress to be most common clinical feature in their studies as well. Furthermore, apart from respiratory distress, lethargy and refusal to feed were considered to be the other common signs and symptoms in studies done by Ganguly et al, ${ }^{[21]}$ and Basu et al. ${ }^{[20]}$ Moreover, the study by Fareedul et al, ${ }^{[10]}$ observed a significant association between definite sepsis and grunting ( $p$-value $=0.015)$ and mottling ( $p$ value 0.015$)$. This was in contrast to our study, where a significant association was found with all clinical features tabulated except vomiting and irritability. This implies that there is no importance of any single clinical feature in predicting definite sepsis, as each factor could be just as likely. This further confirms to the fact 
that the presentation of early onset sepsis is varied and also reiterates the need for laboratory diagnosis for confirmation, rather than relying alone on clinical feature.

$28.3 \%$ of the babies had a positive sepsis screen, which was if two or more criteria were satisfied. Of these, $44.7 \%$ were found to have blood culture positive sepsis, with $\mathrm{p}$ value 0.0001 , which is highly significant.

Out of 300 neonates admitted with suspected early onset sepsis, $70(23.3 \%)$ were diagnosed to have definite sepsis, in terms of blood culture positivity. This was compatible with the incidence of blood culture positivity reported in studies done by Joshi et al, ${ }^{[22]}$ Vandana et al, ${ }^{[23]}$ and Mamta et al, ${ }^{[16]}$ where it was $25 \%, 22 \%$ and $18 \%$ respectively.

The most frequently encountered organism in our study was Klebsiella pneumonia (27.1\%) followed by Staphylococcus hemolyticus (21.4\%) and Acinetobacter (12.8\%). E. coli growth was seen in $8.5 \%$, same as Staphylococcus aureus. Studies done by Indrajit et al, ${ }^{[24]}$ Buch et al, ${ }^{[25]}$ and Mamta et al, ${ }^{[16]}$ also concluded Klebsiella to be most commonly isolated in neonatal early onset sepsis. However, most studies did not mention Acinetobacter as common organism except in DeNIS, ${ }^{[15]}$ collaboration study where it grew in $22 \%$ of the blood cultures. This brings us to the conclusion that though the organisms in the maternal tract still constitute the major source for neonatal early onset sepsis, there is a drift of the organisms from the surrounding environment as well.

In our study, the organisms showed sensitivity to Ampicillin, Gentamicin, Amikacin and Cefotaxime. The combination of Cefotaxime with Amikacin, Ampicillin with Gentamicin and Cefotaxime with Gentamicin was seen to show sensitivity in $70 \%, 70 \%$ and $80 \%$ cases. As a result, it can be considered apt to consider Ampicillin with Gentamicin or Cefotaxime with Amikacin for the empirical treatment of neonatal early onset sepsis.

Neonatal early onset sepsis, one of the major killers in the world of neonatology, remains to be a major disease, whose wide spectrum still poses a challenge to the best of physicians. Its constant evolution, be it in the form of risk factors or presentations or etiology and diagnosis- some olden concepts and facts remain, while new changes are to be incorporated. Thus, it is important for us to repeatedly study the clinical profile of early onset sepsis, to keep in pace with its changes and formulate appropriate guidelines for diagnosis and treatment, in order to restrict it from being a menace.

\section{Conclusion}

Neonatal early onset sepsis remains to be a burden in the state of Odisha, contributing to significant mortality, with preterm and low birth weight children being more vulnerable. Keeping a high index of suspicion in newborns with significant perinatal risk factors such as premature rupture of membranes, birth asphyxia and foul-smelling liquor, along with sepsis screen can help in early identification of early onset sepsis. With changing times, the microbiological spectrum of early onset sepsis seems to be widening and this calls for need to update our protocols and antibiotic policies accordingly, in order to abate the dangers of neonatal early onset sepsis.

\section{References}

1. Black RE, Cousens S, Johnson HL, Lawn JE, Rudan I, Bassani DG, et al. Global, regional, and national causes of child mortality in 2008: a systematic analysis. Lancet. 2010;375(9730):1969-1987. Available from: https://dx.doi. org/10.1016/s0140-6736(10)60549-1.

2. Bang AT, Bang RA, Baitule SB, Reddy MH, Deshmukh MD. Effect of home-based neonatal care and management of sepsis on neonatal mortality: field trial in rural India. Lancet. 1999;354(9194):1955-1961. Available from: https://dx.doi. org/10.1016/s0140-6736(99)03046-9.

3. Stoll BJ, Hansen NI, Sanchez PJ, Faix RG, Poindexter BB, Meurs KPV, et al. Early Onset Neonatal Sepsis: The Burden of Group B Streptococcal and E. coli Disease Continues. Pediatr. 2011;127(5):817-826. Available from: https://dx.doi.org/10. 1542/peds.2010-2217.

4. Shane A, Sánchez PJ, Stoll BJ. Neonatal sepsis. Lancet. 2017;S0140-6736(17):31002-31006. Available from: https: //doi.org/10.1016/S0140-6736.

5. Escobar GJ. The neonatal "sepsis work-up": Personal reflections on the development of an evidence-based approach toward newborn infections in a managed care organization. Pediatrics. 1999;103(1 Suppl E):360-73.

6. Gerdes JS, Polin R. Early diagnosis and treatment of neonatal sepsis. Indian J Pediatr. 1998;65(1):63-78. Available from: https://dx.doi.org/10.1007/bf02849696.

7. Singh M, Narang A, Bhakoo ON. Predictive Perinatal Score in the Diagnosis of Neonatal Sepsis. J Trop Pediatr. 1994;40(6):365-368. Available from: https://dx.doi.org/10. 1093/tropej/40.6.365.

8. Polinski C. The value of white blood cell count and differential in the prediction of neonatal sepsis. Neonatal Netw. 1996;15:13-23.

9. Silva OD, Ohlsson A, Kenyon C. Accuracy of leukocyte indices and C-reactive protein for diagnosis of neonatal sepsis. Pediatr Infect Dis J. 1995;14(5):362-366. Available from: https://dx.doi.org/10.1097/00006454-199505000-00005.

10. Fareedul H, Shamshad K, Prakash S. Clinical Profile and Risk factors in Neonatal Sepsis. IOSR-J Dent Med Sci . 2017;13(12):44-47. Available from: https://dx.doi.org/10. 9790/0853-131264447.

11. Murthy S, Godinho MA, Guddattu V, Lewis LES, Nair NS. Risk factors of neonatal sepsis in India: A systematic review and meta-analysis. PLOS One. 2019;14(4):e0215683e0215683. Available from: https://dx.doi.org/10.1371/journal. pone. 0215683 .

12. Oddie S. Risk factors for early onset neonatal group B streptococcal sepsis: case-control study. BMJ. 2002;325(7359):308- 
308. Available from: https://dx.doi.org/10.1136/bmj.325.7359. 308.

13. Shah GS, Budhathoki S, Das BK, Mandal RN. Risk factors in early neonatal sepsis. Kathmandu Univ Med J. 2006;4(2):187191.

14. Benitz WE, Gould JB, Druzin ML. Risk Factors for Early-onset Group B Streptococcal Sepsis: Estimation of Odds Ratios by Critical Literature Review. Pediatrics. 1999;103(6):e77-e77. Available from: https://dx.doi.org/10.1542/peds.103.6.e77.

15. Delhi Neonatal Infection Study (DeNIS) collaboration.Characterisation and antimicrobial resistance of sepsis pathogens in neonates born in tertiary care centres in Delhi, India: a cohort study. Lancet Glob Health. 2016;4:752-60. Available from: https://dx.doi.org/10.1016/S2214-109X(16) 30148-6.

16. Jajoo M, Kapoor K, Garg LK, Manchanda V, Mittal SK. To study the incidence and risk factors of early onset neonatal sepsis in an out born neonatal intensive care unit of India. J Clin Neonatol. 2015;4(2):91-91. Available from: https://dx.doi.org/ 10.4103/2249-4847.154106.

17. Agarwal M, Chathurvedi P, Dey SK, Narang P. Coagulase negative staphylococcal septicemia in newborn. Indian Pediatr. 1990;27:163-169.

18. Chacko B, Sohi I. Early Onset Neonatal Sepsis. Indian J Pediatr. 2005;72(1):23-23. Available from: https://dx.doi.org/ 10.1007/BF02760574.

19. Pokhrel B, Koirala T, Shah G, Joshi S, Baral P. Bacteriological profile and antibiotic susceptibility of neonatal sepsis in neonatal intensive care unit of a tertiary hospital in Nepal. BMC Pediatr. 2018;18(1):208-208. Available from: https://dx.doi. org/10.1186/s12887-018-1176-x.

20. Basu R, Bandyopadhyay S. Study on Correlation between Sepsis Screening and Blood Culture in Neonatal Sepsis. IOSR-J Dent Med Sci. 2014;13(5):52-56. Available from: http://www. iosrjournals.org/.
21. Nandy M, Dutta S, Ganguly S, Dk P, Bandhopadhyay M. Changes in the Incidence and Spectrum of Neonatal Septicemia During a Fifteen-Year Period. Child New Born. 2007;11(1):36. Available from: https://dx.doi.org/10.1111/j.1651-2227. 1985.tb10014.x.

22. Joshi SG, Ghole VS, Niphadkar KB. Neonatal gram-negative bacteremia. Indian J Pediatr. 2000;67(1):27-32. Available from: https://dx.doi.org/10.1007/bf02802632.

23. Vandana G, rao magar SL, Praveen D, devi BK, rani S, anil S. IOSR-J Dent Med Sci . 2017;16:11-17. Available from: https://dx.doi.org/10.9790/0853-1604091117.

24. Gupta I, Naskar P, Mitra G. Spectrum of Bacterial Infection and Antimicrobial Sensitivity Pattern in Neonatal Septicemia in a Peripheral Tertiary Care Hospital in West Bengal. Indian J Comm Med. 2016;3(9):34-38.

25. Buch A, Shrivastava, Kumar H, Jadhav P. Evaluation of hematological profile in early diagnosis of clinically suspected cases of neonatal sepsis. Int J Bams. 2011;1(1):1-06. Available from: http://www.cibtech.org/jms.htm.

Copyright: (C) the author(s), 2020. It is an open-access article distributed under the terms of the Creative Commons Attribution License (CC BY 4.0), which permits authors to retain ownership of the copyright for their content, and allow anyone to download, reuse, reprint, modify, distribute and/or copy the content as long as the original authors and source are cited.

How to cite this article: Pankaj KC, Ganguly S, Upadhyay MR Clinical Profile of Neonatal Early Onset Sepsis: A Study on the Current Scenario. Asian J. Clin. Pediatr. Neonatol. 2020;8(2):3641.

DOI: dx.doi.org/10.47009/ajcpn.2020.8.2.7

Source of Support: Nil, Conflict of Interest: None declared. 